\title{
Visceral dissemination of herpes zoster with multiple ulcers in the upper gastrointestinal tract of an apparently immunocompetent patient
}

Visceral dissemination of varicella zoster virus (VZV) may follow cutaneous infection in immunocompromized patients (e.g. bone marrow transplant recipients) [1]. However, involvement of the upper gastrointestinal tract is rare [1-4].

An 81-year-old man underwent upper endoscopy for heartburn, nausea, and vomiting. There was no prior history of clinically overt immunodeficiency. Endoscopy revealed multiple small, superficial ulcers in the esophagus, the gastric corpus and antrum, and the duodenum ( $\bullet$ Fig. 1 a-c). A few days prior to endoscopic evaluation, the patient had developed a few vesicular eruptions over his head and trunk $($ Fig. 1d).

Histological examination of the biopsy specimens revealed acantholysis and ballooning of keratinocytes in the esophagus $(\bullet$ Fig.2a). Gastric and duodenal ulcerations were surrounded by a prominent histiocytic infiltrate. Epithelial and stromal cells showed viral cytopathic changes including enlarged hyperchromatic nuclei with uneven borders. Nuclei appeared molded with chromatin margination and a "ground glass" appearance. Single viral inclusions were present ( $\bullet$ Fig. 2 b). Polymerase chain reaction of samples from esophageal and gastric biopsies showed positive amplification of VZV DNA (44 kDa protein gene).

The patient improved considerably after the initiation of treatment with acyclovir $10 \mathrm{mg} / \mathrm{kg}$ three times daily for 10 days.

Multifocal gastrointestinal involvement with VZV following cutaneous dissemination is uncommon even in immunocompromized hosts, and has not been reported in apparently immunocompetent patients up to now [1]. After initial infection has occurred, the virus enters a latent stage in the dorsal root ganglia [1]. Poste-
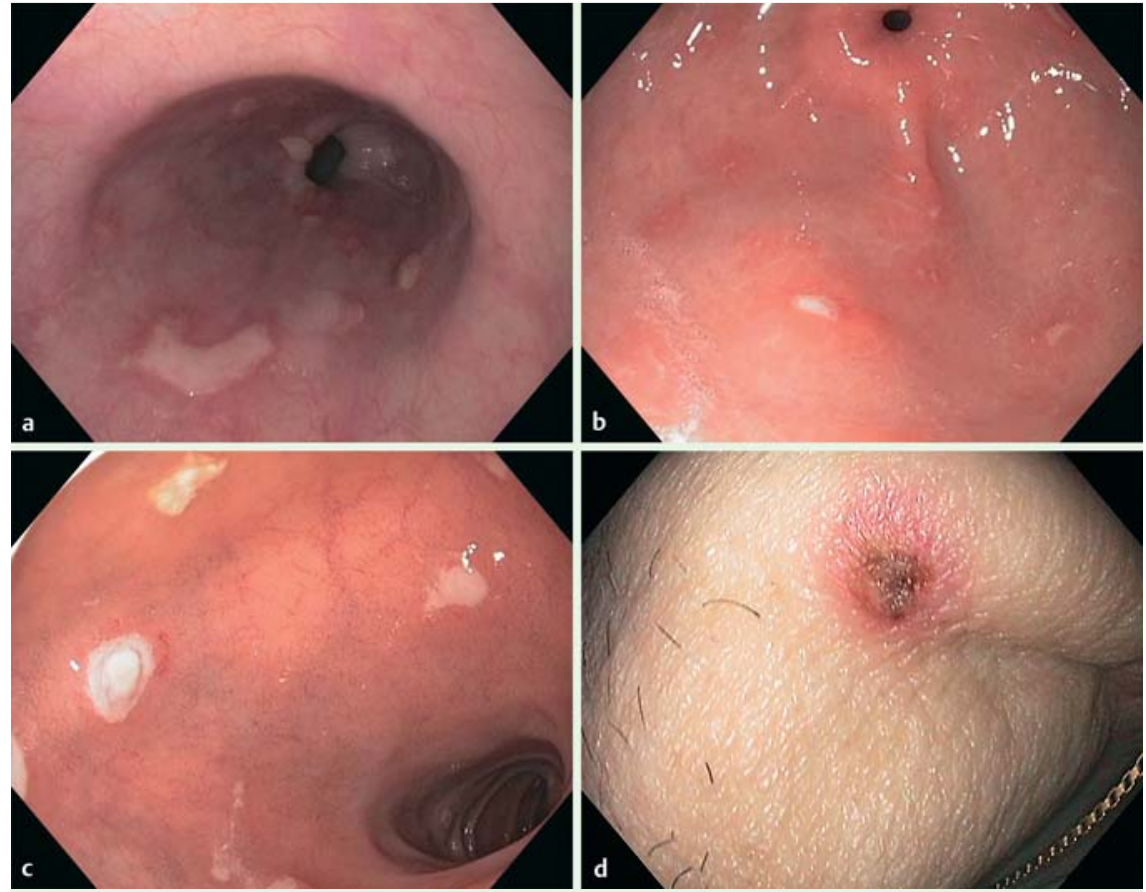

Fig. 1 Small superficial ulcers in the: a esophagus, $\mathbf{b}$ antrum, $\mathbf{c}$ duodenum. $\mathbf{d}$ Encrusted vesicular skin eruption on the patient's neck.

rior sensory nerve roots contain nerve fibers from both the skin and the inner organs $[1,5]$. Reactivation of latent VZV may thus lead to a centrifugal spread toward the skin, as well as a centripetal spread towards the visceral organs $[1,5]$. The present case illustrates the potential visceral dissemination of herpes zoster, causing multiple ulcers throughout the upper gastrointestinal tract of an apparently immunocompetent individual.

\section{Endoscopy_UCTN_Code_CCL_1AB_2AD_3AC}

Competing interests: None

\section{E. Krones ${ }^{1}$, W. Petritsch ${ }^{1}$, T. Valentin ${ }^{2}$, F. Durchschein ${ }^{1}$, G. Gorkiewicz ${ }^{3}$}

${ }^{1}$ Department of Internal Medicine, Division of Gastroenterology and Hepatology, Medical University Graz, Graz, Austria

${ }^{2}$ Department of Internal Medicine, Division of Pulmonology, Medical University Graz, Graz, Austria

${ }^{3}$ Institute of Pathology, Medical University Graz, Graz, Austria 


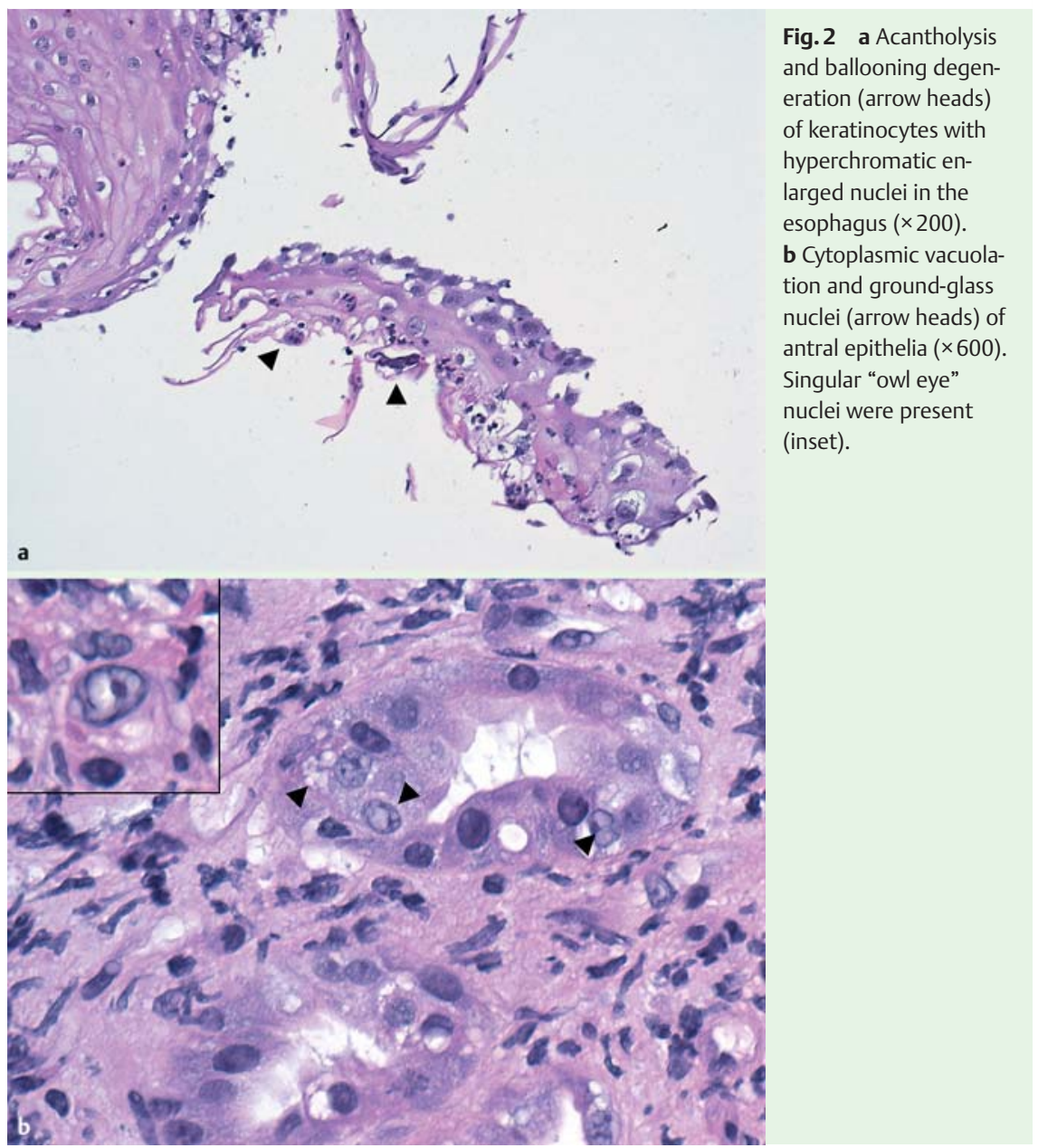

\section{References}

1 Stratman E. Visceral zoster as the presenting feature of disseminated herpes zoster. J Am Acad Dermatol 2002; 46: 771 - 774

2 McCluggage WG, Fox JD, Baillie KE et al. Varicella zoster gastritis in a bone marrow transplant recipient. J Clin Pathol 1994; 47: $1054-1056$

3 Rivera P, Canelles P, Quiles F et al. Gastrointestinal involvement in infections caused by varicella virus. Endoscopy 1998; 30: S9

4 Takatoku M, Muroi K, Kawano-Yamamoto C et al. Involvement of the esophagus and stomach as a first manifestation of varicella zoster virus infection after allogeneic bone marrow transplantation. Intern Med 2004; 43: $861-864$

5 Wisloff F, Bull-Berg J, Myren J. Gastric involvement in herpes zoster. Endoscopy 1980; 12: 134-135

\section{Bibliography}

DOI http://dx.doi.org/

10.1055/s-0032-1309926

Endoscopy 2012; 44: E302-E303

(c) Georg Thieme Verlag KG

Stuttgart · New York

ISSN 0013-726X

\section{Corresponding author}

\section{E. Krones, MD}

Medical University of Graz

Auenbruggerplatz 15

8036 Graz

Austria

Fax: +43-316-38517108

elisabeth.krones@medunigraz.at 